\title{
Significance of ocular stem cells in tissue engineering of the eye
}

\author{
Radiana D Antarianto
}

\begin{abstract}
Abstrak
Masalah kebutaan adalah salah satu masalah kesehatan yang memprihatinkan. Kedokteran regeneratif lewat rekayasa jaringan dan optimalisasi regenerasi jaringan melalui sel induk lokal atau transplantasi sel induk telah mendapat banyak perhatian. Tinjauan pustakan kali ini membahas penemuan penting sel induk mata dan eksperimen in vivo transplantasi sel induk serta tren terkini di bidang rekayasa jaringan mata. (Med J Indones 2008; 17: 143-8)
\end{abstract}

\begin{abstract}
Blindness is one of the most devastating condition for mankind. Regenerative medicine through tissue engineering and optimizing tissue regeneration through local adult stem cell differentiation or stem cell transplantation has received a lot of attention. This review presents highlights in the discovery of ocular stem cell and in vivo experiment for stem cell transplantation and current trends in tissue engineering of the eye. (Med J Indones 2008; 17: 143-8)
\end{abstract}

Keywords: Corneal regeneration, Corneal stem cells, TA cells, CE cells, tissue engineering of the eye

Blindness is one of the most devastating condition for mankind. Regenerative medicine through tissue engineering and optimizing tissue regeneration through local adult stem cell differentiation or stem cell transplantation has gained quite interesting notion.

There is great interest in the biology of adult stem cells (tissue specific stem cells residing in many adult tissue) because of their capacity to self-renew and their high plasticity. These traits enable adult stem cells to produce diverse mature cell progenitors that actively participate in the maintenance of homeostatic processes by replenishing the cells that repopulate the tissues/ organs during a lifespan and regenerate damaged tissues during injury. ${ }^{1,2}$ Structural damage to the eye and their components could also be treated by the stem cell-based therapies.

Widely accepted criteria for defining stem cells are: A) slow cycling or long cell cycle time during homeostasis in vivo; B) poorly differentiated with primitive cytoplasm; C) high capacity for error-free self renewal, and D) activation of proliferation by wounding or placement in culture. ${ }^{1}$

Department of Histology, Faculty of Medicine University of Indonesia, Jakarta, Indonesia
This review presents highlights in the discovery of ocular stem cell and in vivo experiment for stem cell transplantation and current trends in tissue engineering of the eye.

\section{Ocular Stem Cells}

The major markers proposed for epithelial SCs in ocular or non-ocular tissues in the past decade can be categorized into at least three groups: ${ }^{3}$

A) nuclear proteins such as the transcription factor p63

B) cell membrane or transmembrane proteins including integrins (integrin $\beta 1, \alpha 6, \alpha 9$ ), receptors (epidermal growth factor receptor [EGFR], transferrin receptor (CD71), and drug resistance transporters (ABCG-2)

C) cytoplasmic proteins such as cytokeratins (CK) (cytokeratin 19), nestin, and $\alpha$-enolase.

In addition, a variety of differentiation markers have also been proposed to distinguish the SCs from differentiated cells. These include cytokeratins K3 and $\mathrm{K} 12$, involucrin, intercellular adhesive molecule E-cadherin, and gap junction protein connexin 43 , etc. ${ }^{3}$ 
The human ocular surface epithelium includes the corneal, limbal, and conjunctival stratified epithelia. Several recent lines of evidence have revealed that the corneal epithelial stem cells (CESCs) are localized at the basal cell layer of the peripheral cornea, and particularly at the limbus within the limbal epithelial crypts. ${ }^{4-7}$ The limbal CESCs, which express several markers, including p63, ABCG2, $\alpha 9$ - and $\beta 1$-integrins, EGFR, K19, $\alpha$-enolase, and CD71, possess the ability to reconstitute an intact and functional corneal epithelium in vivo. ${ }^{3,4,7}$

More specifically, CESCs can give rise to the progenitors that are able to migrate at the corneal epithelium. These corneal cell progenitors show a rate of proliferation inferior to that of CESCs in vitro and correspond to a basal cell population that is involved in the replenishment of the corneal epithelium cells, which have a limited lifespan of less than 1 year. ${ }^{4}$

The supporting data for the limbal location of CESCs include:

A) the limbal basal cells lack the corneal epithelial differentiation-associated keratin pair $\mathrm{K} 3$ and $\mathrm{K} 12 .{ }^{8,9}$

B) the limbal basal epithelium contains slow-cycling cells identified as the "label-retaining cells" following pulse-chase labeling ofall cells with a DNA precursor, such as [3H]-thymidine or bromodeoxyuridine (BrdU), and the limbal basal epithelium exhibits high proliferative potential in culture..$^{10-12}$

C) experimental studies and clinical observations show abnormal corneal epithelial wound healing with conjunctivalization, vascularization, and chronic inflammation when the limbal epithelium is partially or completely defective..$^{13-16}$

D) limbal cells are essential for the long-term maintenance of the central corneal epithelium, and they can be used to reconstitute the entire corneal epithelium in patients with limbal SC deficiencies. ${ }^{17,18}$

The conjunctival epithelial stem cells appear to be enriched in the bulbar and forniceal conjunctiva. ${ }^{3}$

In addition, it has been reported that the putative stem cells, which are sequestered in a niche localized at the region between the corneal endothelium cells and the trabecular meshwork, may also give rise to both the corneal endothelium and trabeculae. These stem cellderived TA cells could also migrate at the endothelial periphery, suggesting their possible implication in eye endothelium regeneration. ${ }^{3}$

A small population of mitotic quiescent neural stem cells has also been identified in the ciliary epithelium (CE) region adjacent to the retina in adult mammalian eyes, which may proliferate in response to retinal injury in vivo or after treatment with specific exogenous growth factors in vitro. These multipotent CESCs also designated retinal stem cells (RSCs), which are able to self-renew, express several specific stem cell markers, including telomerase, neural markers such as nestin, and retinal progenitor markers such as Pax 6..$^{19,20}$

RSCs in CE may differentiate in vitro into distinct adult retinal progenitor populations, including retinal ganglion cells, as well as rod photoreceptors, bipolar cells, and Müller glia, which are derived from early and late stages of retinal histogenesis, respectively. Analysis of the gene expression pattern indicated that RSCs show more resemblances to early than late born retinal neurons. ${ }^{20,21}$ More particularly, RSCs express the higher levels of FGF receptor 1 than EGFR and respond preferentially to bFGF than EGF in vitro. This then suggests that RSCs in CE may represent a primitive cell population that may respond preferentially to $\mathrm{bFGF}$ at early differentiating stage and, subsequently, to EGF at a later stage. ${ }^{20,22}$

The proliferation and/or differentiation of RSCs in $\mathrm{CE}$ may also be regulated through the activation of other mitogenic and differentiation signaling, such as hedgehog, KIT, and Notch signaling pathways, which are also known to be important regulators of neurogenesis. ${ }^{20,21,23}$ The intraocular injection of SHH results in stimulation of the proliferation of RSCs in $\mathrm{CE}$, whose proliferative effect was also inhibited in the presence of the Smoothened (SMO) signaling element inhibitor, cyclopamine. ${ }^{23}$

\section{Animal Model of Cornea Regeneration post Conductive Keratoplasty ${ }^{24}$}

Conductive keratoplasty generates heat in the cornea by using the electrical conductive properties of the corneal tissue. The resistance to the current flow through the corneal tissue, and not the probe itself, generates the thermal energy. The current propagates along undenatured corneal tissue, resulting in a homogeneous thermal footprint that is thought to 
minimize regression over time. There was early collagen shrinkage and changes in the composition of the ECM in a homogeneous deep footprint.

Greater amounts of posterior stromal and endothelial injury are observed compared with that in humans because the rabbit cornea is approximately $350 \mathrm{~mm}$ thick, compared with $550 \mathrm{~mm}$ in a normal human cornea. These changes certainly explain the immediate corneal steepening observed after CK. However, the collagen rapidly regained its original configuration and at 4 weeks, it gained its original appearance. These events may explain the initial regression observed after CK. However, there is some effect produced by the surgery after the collagen regains its original configuration. At this point, other structural changes are responsible for the corneal steepening observed.

Matrix metalloproteinases (MMP) are a group of enzymes that degrade the ECM. Collagen, which is the main component of the corneal stroma, is a substrate of MMP-1 or collagenase-1. Along with its tissue inhibitors, MMPs assist in the regulation of the overall remodeling of the ECM components.

An overexpression of MMPs could degrade the corneal matrix. Koch et al. in a rabbit model using 10pulse noncontact Ho:YAG laser thermal keratoplasty described a complex wound-healing response including keratocyte activation, synthesis of type I collagen, partial restoration of the stromal keratin sulfate, and type VI collagen and a retrocorneal membrane formation 3 weeks after the procedure.

One study observed an up-regulation of MMP-1 in the first 2 months following surgery, suggesting that a process of matrix degradation and remodeling is occurring in the stroma adjacent to the surgical injury site. Additionally, an increased number of TUNELpositive cells, which indicate keratocyte apoptosis, and $\alpha$ Smooth Muscle Actin ( $\alpha$ SMA) cells, which indicate the appearance of myofibroblasts, were observed in the cylindrical footprint area underlying each spot. This suggests that the footprint produced by the keratoplast tip induces a full-thickness homogeneous activation of myofibroblasts. These myofibroblasts may be responsible for a continuous matrix remodeling process and the long-term contraction of tissue in that area.

In fact, at 2 weeks, the positive collagen III staining coincides with $\alpha$ SMA, suggesting that these cells could secrete this ECM component. However, there was a gradual reduction in the number of $\alpha$ SMA cells, as well as collagen III, over time, which may explain the keratometric regression detected on corneal topography.

At 6 and 8 weeks, there was a $50 \%$ reduction in the amount of $\alpha$ SMA-positive cells compared with the second postoperative week. The denaturalization and shrinkage of collagen fibers produced by CK may be responsible for the initial and rapid modification of the corneal curvature, but the appearance of myofibroblasts may be responsible for supporting the tension exerted by these changes until they become permanent. In addition, these cells could secrete MMP-1 and increase the synthesis of collagen III. We postulate that both the collagen shrinkage and stromal wound healing are responsible for the regression and/or stabilization of the refractive effect produced by $\mathrm{CK}$.

The up-regulation of myofibroblasts may have a role in the steepening effect of the CK procedure, exerting a tensile force that maintains the collagen shrinkage induced by the radio-frequency energy. Over time, these cells are replaced by normal keratocytes that do not have the capacity to resist tension and, gradually, the effect of the surgery is lost.

Therefore, contrary to LASIK surgery in which the prolonged presence of myofibroblasts are the cause of haze and reduced vision, in $\mathrm{CK}$, prolonging the survival of stromal myofibroblasts in the area of the injury may be an approach to maintain the corneal shape.

It is important, however, to recognize the limitations of the rabbit model in assessing the nature of the wound-healing response in humans. Wound healing is much more vigorous in rabbits, and many differences exist.

\section{Stem Cells as definitive therapy for Ocular Disorders and Diseases}

CESCs and RSCs, isolated from the limbal epithelium and CE ofadult eyes, respectively, are able to incorporate and reconstitute the damaged tissues in vivo. Therefore, they may be transplanted for the repair and regeneration of ocular surface damages. ${ }^{6}$

Several types of treatment for ocular disorders have been developed based on the use of limbal CESC transplants for the replacement of ocular damaged tissues. More specifically, the choice of treatment 
depends on several factors, including the severity of corneal damage and the degree of limbal CESC loss. In a situation where the limbal area of the peripheral cornea is destroyed, such as in the Stevens-Johnson syndrome, ocular pemphigoid, and severe ocular burns, limbal CESC grafts combined with amniotic membrane transplantation might be used for reconstruction of the ocular surface..$^{25,26}$

A new strategy for the treatment of limbal CESC deficiency includes a limbal biopsy in healthy donor eyes followed by the ex vivo expansion of limbal CESCs by using a substrate such as human amniotic membrane carrier, in which the cells might proliferate, migrate, and regenerate a new tissue. ${ }^{6,26,27}$ Hence, this strategy provides the bioengineered corneal surface tissues with anti-angiogenic and anti-inflammatory properties due to the presence of amniotic membrane; the corneal surface tissues might be successfully transplanted onto diseased eyes to restore the structure and function of damaged ocular surfaces and the visual acuity. For instance, the results from a survival analysis of conjunctival limbal grafts concomitant with amniotic membrane transplantation in 33 eyes from 31 patients with total limbal CESC deficiency have indicated a graft cumulative survival of $33 \%$ after a mean follow-up time of 33 months. ${ }^{28}$ There was an increase in postoperative visual acuity in $60.6 \%$ of patients during this period. ${ }^{28}$

Reconstruction of chemically burned rat corneal surfaces has also been performed by using human MSCs from healthy donors after expansion on amniotic membrane..$^{29}$ In fact, the therapeutic effect of the MSC transplantation may also be due, in part, to an inhibition of inflammatory and angiogenic processes rather than the epithelial differentiation of MSCs. ${ }^{29}$

\section{Tissue Engineering of the eye}

A study to culture retinal pigment epithelial (RPE) and corneal endothelial cells on biodegradable substrates was done for future implementation in monolayer transplantation of the eye. The biodegradable polymers, poly-L-lactic (PLLA) and poly-DL-lactic-co-glycolic acid (85:15) (PLGA) (both of molecular weight $105 \mathrm{kd}$ ) were the biomaterials used. All materials were seeded with either pig/human retinal pigment epithelial cells or rabbit corneal endothelial cells and were maintained in tissue culture conditions. Upon confluency, the cell density was calculated and cell viability determined. All monolayers were stained with phalloidin-rhodamine for F-actin and antibodies to the tight junction (zonula occludens) protein, $\mathrm{ZOi}$, to demonstrate the presence of tight junctions. The final cell density of human RPE monolayers on PLLA films was 2950 cells/mm2 ( \pm 185$)$. The final cell density of pig RPE on PLLA and PLGA film was 2350 cells $/ \mathrm{mm} 2$ ( \pm 152 and 178 , respectively). Rabbit corneal endothelial cells had a final cell density of 2650 cells $/ \mathrm{mm} 2( \pm 164)$. F-actin staining revealed a circumferential ring of actin filaments in all of the cells grown on substrates. ZOi immunohistochemistry demonstrated staining along the lateral cell borders of all cell types. The successful culture of retinal pigment epithelial and corneal endothelial monolayers on these substrates may have potential for transplanting cell monolayers in the eye to improve vision. ${ }^{30}$

Another study on polyglycolic acid (PGA) scaffold bearing an adherent corneal stromal cell insert are integrated into the ultrastructure of rabbit corneal stroma without compromising tissue transparency. Stromal cells were isolated from 10 newborn rabbits and expanded by tissue culture. After reaching confluence, the cells were harvested and mixed with nonwoven PGA fibers to form cell-scaffold constructs. After 1 week of culturing, they were implanted into the corneal stroma of female rabbit recipients. Green fluorescent protein (GFP) expression in transplanted corneal stromal cells was monitored at the protein level to determine cellular origin in the reconstructed stroma. Eight weeks after implantation, transmission electron microscopy and histological evaluation were performed on stromal tissue. Insertion of PGA scaffold alone served as a sham control. After stromal implantation, implants gradually became transparent over an 8-week period. During this time stromal histology was gradually restored, as collagen fibril organization approached that of their normal counterpart. GFP-labeled corneal stromal cells were preponderant in the regions bearing inserted scaffolds, suggesting that they were derived from the implants rather than from neighboring corneal stromal cells. No reconstructed stroma developed in regions where naked PGA was implanted instead. Intrastromal implantation of PGA fiber scaffold implants bearing corneal stromal cells is a useful procedure for corneal stromal tissue reconstruction because, over an 8-week period, the implants become progressively more transparent. Marked losses of translucence during this period combined with restoration of ultrastructure indicate that the implants provide the functions needed for deturgescing initially swollen stroma. ${ }^{31}$ 
A technique for determining donor cell fate following corneal grafting was evaluated. Patients treated for limbal deficiency with allogeneic cultured corneal epithelial cells were studied to determine the fate of the grafted cells. The technique was evaluated initially through the use of donor eyes and then applied to the clinical analysis of 7 patients who had received a cultured corneal epithelial allograft. Cells removed from the cornea and any retrieved tissue were analyzed via polymerase chain reaction (PCR) genotyping to determine the origin of the cells populating the patients' healed cornea. A mixture of genotypes was detected in a cornea retrieved from a patient following a fully penetrating keratoplasty who had received a mixture of allogeneic tissue. Donor cells were no longer detected on the corneal surface of all 7 cases beyond 28 weeks postgraft. At these later time points, only patient genotype could be detected. These results demonstrate that PCR genotyping can be used to determine the origin of cells populating the surface of the cornea following the grafting of cultured allogeneic cells and demonstrates that transplanted cultured limbal epithelial cells do not persist on the surface of the host cornea for more than 28 weeks. ${ }^{32}$

Choroidal neovascularization (CNV) is the most severe form of age-related macular degeneration (AMD), which causes rapid visual loss. Transplantation of cultured retinal pigment epithelium (RPE) cell sheet by tissue engineering is a possible approach to the treatment of $\mathrm{CNV}$. The possibility of using magnetite nanoparticles and magnetic force to construct and deliver RPE cell sheets in vitro was investigated. When magnetite cationic liposomes (MCLs), having a positive charge at the surface, were added to ARPE-19 human RPE cells at a concentration of 25 or $50 \mathrm{pg}$ of magnetite per cell, the cells took up 40 to $55 \%$ of the MCLs. The magnetically labeled ARPE-19 cells $(8 \times 103$ cells $/ \mathrm{mm} 2$, which corresponds to 10 -fold the confluent concentration against the culture area [4 $\mathrm{mm} 2]$ ) were seeded into an ultra-low-attachment plate and a magnet $(4000 \mathrm{G})$ was placed under the well. The magnetically labeled ARPE19 cells formed an approximately 15 -layered cell sheet after a $24 \mathrm{~h}$ of culture. When the magnet was removed, the sheets were detached from the bottom of the plate and then harvested and transferred to a tissue culture dish, using a magnet. Subsequently, the cell sheets were attached onto the dish, and the cells growing on the sheets were observed. This novel methodology, termed "magnetic force-based tissue engineering" (Mag-TE), is a possible approach for $\mathrm{CNV}$ treatment. ${ }^{33}$
Based on mediated transfection technique, there's in vivo protocol for an efficient transfer of plasmid DNA to ocular cells. As determined with condensed plasmids containing reporter genes for either $\beta$-galactosidase (pcDNA-lacZ) or enhanced green fluorescent protein (pREP-EGFP), the immortalized human retinal epithelial cells RPE D407 and human embryonic kidney 293 cells can be transfected with typical efficiencies of 11 and 19\%, respectively. Unlike 293 cells, RPE D407 cells had a reduced viability on transfection with both plasmids. In vivo, subretinal injections of DNA-K8/ JTS-1 complexes revealed reporter gene expression in choroidal and RPE cells of normal pink-eyed Royal College of Surgeons (RCS) rats. The validity of this transfection technique in terms of retinal cell survival in RCS rats was then examined by using pREP-hFGF2 plasmid, which encodes the human basic fibroblast growth factor isoforms (hFGF2). Subretinal injection of pREP-hFGF2-K8/JTS-1 complexes into 3-week-old dystrophic RCS rat eyes reveals a delayed photoreceptor cell degeneration 60 days postinjection. In this case, the average analyzed field points with delayed cell dystrophy represent 14 to $17 \%$ of the retinal surface as compared with 2.6 and $4 \%$ in pREP5 $\beta$ and vehicleinjected eyes, respectively. Peptide-mediated in oculo transfection thus appears to be a promising technique for the treatment of retinal cell and photoreceptor degenerations. ${ }^{34}$

\section{CONCLUSION}

- Ocular stem cells of the eye identification are through nuclear transcription factor p63, membrane/ transmembrane protein and cytoplasmic protein (cytokeratin)

- Amongst ocular stem cells identified are: Corneal epithelial stem cells, limbal epithelial derived-TA cells, and Ciliary epithelium (CE) or designated Retinal Stem Cells (RSCs)

- Ocular stem cell transplantation has been performed in animal model

- Tissue engineering of the eye including studies on biodegradable material, culture and graft, and mediated transfection technique.

\section{REFERENCES}

1. Mimeault M, Batra SK. Concise Review: Recent Advances on the Significance of Stem Cells in Tissue Regeneration and Cancer Therapies. Stem Cells. 2006; 24(11): 2319-2345. Cited from http://www.stemcells.com/ on $1^{\text {st }}$ March 2007. 
2. Gartner LP, Hiatt JL. Color Textbook of Histology. $3^{\text {rd }}$ ed. Philadelphia:WB Saunders Company ;2007

3. Chen Z, de Paiva CS, Luo L, et al. Characterization of Putative Stem Cell Phenotype in Human Limbal Epithelia. Stem Cells. 2004;22:355-366. Cited from http://www. stemcells.com/ on $1^{\text {st }}$ March 2007.

4. Lavker RM, Tseng SC, Sun TT. Corneal epithelial stem cells at the limbus: Looking at some old problems from a new angle. Exp Eye Res 2004;78:433-446.

5. Pellegrini G, Dellambra E, Paterna $P$ et al. Telomerase activity is sufficient to bypass replicative senescence in human limbal and conjunctival but not corneal keratinocytes. Eur J Cell Biol 2004;83:691-700.

6. Ang LP, Tan DT. Ocular surface stem cells and disease: Current concepts and clinical applications. Ann Acad Med Singapore 2004;33:576-580.

7. Dua HS, Shanmuganathan VA, Powell-Richards AO et al. Limbal epithelial crypts: A novel anatomical structure and a putative limbal stem cell niche. Br J Ophthalmol 2005;89:529-532.

8. Kurpakus MA, Maniaci MT, Esco M. Expression of keratins $\mathrm{K} 12, \mathrm{~K} 4$, and K14 during development of ocular surface epithelium. Curr Eye Res 1994;13:805-814

9. Cotsarelis G, Cheng SZ, Dong G et al. Existence of slowcycling limbal epithelial basal cells that can be preferentially stimulated to proliferate: implications on epithelial stem cells. Cell 1989;57:201-209.

10. Ebato B, Friend J, Thoft RA. Comparison of limbal and peripheral human corneal epithelium in tissue culture. Invest Ophthalmol Vis Sci 1988;29:1533-1537.

11. Kruse FE, Tseng SC. A tumor promoter-resistant subpopulation of progenitor cells is larger in limbal epithelium than in corneal epithelium. Invest Ophthalmol Vis Sci 1993;34:2501-2511.

12. Pellegrini G, Golisano O, Paterna P et al. Location and clonal analysis of stem cells and their differentiated progeny in the human ocular surface. J Cell Biol 1999;145:769-782.

13. Chen JJ, Tseng SC. Corneal epithelial wound healing in partial limbal deficiency. Invest Ophthalmol Vis Sci 1990;31:1301-1314.

14. Chen JJ, Tseng SC. Abnormal corneal epithelial wound healing in partial-thickness removal of limbal epithelium. Invest Ophthalmol Vis Sci 1991;32:2219-2233.

15. Huang AJ, Tseng SC. Corneal epithelial wound healing in the absence of limbal epithelium. Invest Ophthalmol Vis Sci 1991;32:96-105.

16. Jenkins $\mathrm{C}$, Tuft $\mathrm{S}$, Liu $\mathrm{C}$ et al. Limbal transplantation in the management of chronic contact-lens-associated epitheliopathy. Eye 1993;7:629-633.

17. Tseng SC. Concept and application of limbal stem cells. Eye 1989;3:141-157.

18. Tsai RJ, Li LM, Chen JK. Reconstruction of damaged corneas by transplantation of autologous limbal epithelial cells. N Engl J Med 2000;343:86-93.

19. Ahmad I, Das AV, James J et al. Neural stem cells in the mammalian eye: Types and regulation. Semin Cell Dev Biol 2004; 15:53-62.
20. Das AV, James J, Rahnenfuhrer J et al. Retinal properties and potential of the adult mammalian ciliary epithelium stem cells. Vision Res 2005;45:1653-1666.

21. James J, Das AV, Rahnenfuhrer $\mathrm{J}$ et al. Cellular and molecular characterization of early and late retinal stem cells per progenitors: Differential regulation of proliferation and context dependent role of Notch signaling. J Neurobiol 2004;61:359-376.

22. Liu IH, Chen SJ, Ku HH et al. Comparison of the proliferation and differentiation ability between adult rat retinal stem cells and cerebral cortex-derived neural stem cells. Ophthalmologica 2005;219:171-176.

23. Moshiri A, McGuire CR, Reh TA. Sonic hedgehog regulates proliferation of the retinal ciliary marginal zone in posthatch chicks. Dev Dyn 2005;233:66-75.

24. Esquenazi S, He J, Kim DB, et al. Wound-healing response and refractive regression after conductive keratoplasty. J Cataract Refract Surg 2006; Vol 32: 480-486.

25. Dogru M, Tsubota K. Current concepts in ocular surface reconstruction. Semin Ophthalmol 2005;20:75-93.

26. Gomes JA, Romano A, Santos MS et al. Amniotic membrane use in ophthalmology. Curr Opin Ophthalmol 2005;16:233-240.

27. Nakamura T, Inatomi T, Sotozono $\mathrm{C}$ et al. Successful primary culture and autologous transplantation of corneal limbal epithelial cells from minimal biopsy for unilateral severe ocular surface disease. Acta Ophthalmol Scand 2004;82:468-471.

28. Santos MS, Gomes JA, Hofling-Lima AL et al. Survival analysis of conjunctival limbal grafts and amniotic membrane transplantation in eyes with total limbal stem cell deficiency. Am J Ophthalmol 2005;140:223-230.

29. Ma Y, Xu Y, Xiao Z et al. Reconstruction of chemically burned rat corneal surface by bone marrow-derived human mesenchymal stem cells. STEM CELLS 2006;24:315-321.

30. Hadlock T, Singh S, Vacanti JP, Mclaughlin BJ. Ocular Cell Monolayers Cultured on Biodegradable Substrates. Tissue Engineering 1999; Vol. 5(3) : 187 -196.

31. Hu X, Lui W, Cui L, et al. Tissue Engineering of Nearly Transparent Corneal Stroma. Tissue Engineering 2005; Vol. 11(11-12) : 1710 - 1717.

32. Sharpe JR, Daya SM, Dimitriadi M, et al. Survival of Cultured Allogeneic Limbal Epithelial Cells Following Corneal Repair. Tissue Engineering 2007; Vol. 13(1) : 123 -132 .

33. Ito A, Hibino E, Kobayashi C, et al. Construction and Delivery of Tissue-Engineered Human Retinal Pigment Epithelial Cell Sheets, Using Magnetite Nanoparticles and Magnetic Force. Tissue Engineering 2005; Vol. 11(3-4) : $489-496$.

34. Neuner-Jehle M, van den Berghe L, Bonnel S, et al. Ocular Cell Transfection with the Human Basic Fibroblast Growth Factor Gene Delays Photoreceptor Cell Degeneration in RCS Rats. Human Gene Therapy 2000; Vol. 11(13) : 1875 -1890 . 